\title{
IL-1 $\beta$ in irrigation fluid and mRNA expression in synovial tissue of the knee joint as therapeutic markers of inflammation in collagen antibody-induced arthritis
}

\author{
Wei-Tso Chia ${ }^{\mathrm{a}, \mathrm{b}}$, Li-Tzu Yeh ${ }^{\mathrm{b}}$, Yuan-Wu Chen ${ }^{\mathrm{b}}$, Herng-Sheng Lee ${ }^{\mathrm{b}}$, Deh-Ming Chang ${ }^{\mathrm{b}}$ and \\ Huey-Kang Sytwu ${ }^{\mathrm{b}, *}$ \\ ${ }^{a}$ Hsin Chu General Hospital, Department of Health, Executive Yuan, Taiwan \\ ${ }^{\mathrm{b}}$ Graduate Institute of Medical Sciences, National Defense Medical Center, Taipei, Taiwan
}

\begin{abstract}
Objective: We studied the relationship between the severity of inflammation and IL-1 $\beta$ production and relative expression level of IL-1 $\beta$ mRNA in irrigation fluid and synovial tissue obtained from the knee joint during the acute stage of a murine model of type II collagen antibody-induced arthritis (CAIA). This model is used to identify potential therapeutic markers for treating rheumatoid arthritis.

Methods: Irrigation fluid and synovium tissue were harvested from the knee joint of BALB/c mice in acute stage of CAIA induction. The IL-1 $\beta$ protein level was measured by enzyme-linked immunosorbent assay, and the relative expression level of IL-1 $\beta$ mRNA was analyzed by reverse transcription-polymerase chain reaction. Two investigators analyzed expression levels and histopathological changes.

Results: IL- $1 \beta$ concentration was higher in irrigation fluid from the knee joint than in the serum in the acute stage of CAIA. The relative expression level of IL-1 $\beta$ mRNA was elevated in synovial tissue. Histopathological changes in the knee joint and foot indicated similar severity.

Conclusions: IL-1 $\beta$ concentration in irrigation fluid and relative expression level of IL-1 $\beta$ mRNA in the synovium have potential as therapeutic markers in studying and treating CAIA.
\end{abstract}

\section{Introduction}

Rheumatoid arthritis (RA) is a chronic autoimmune disease affecting primarily the synovial tissue in many joints. RA causes pannus formation and joint destruction $[1,2]$. Anti-type II collagen antibody is an autoantibody that appears in the blood of patients with RA [3]. The collagen-induced arthritis (CIA) model is the most commonly used animal model of RA. Collagen type

\footnotetext{
* Corresponding author: Huey-Kang Sytwu, MD, PhD, Graduate Institute of Medical Sciences and Department of Microbiology and Immunology, National Defense Medical Center, 161, Section 6, MinChuan East Road, Neihu, Taipei, Taiwan 114. Tel.: +886 287923100 18540; E-mail: sytwu@ndmctsgh.edu.tw.
}

II (CII) is a major constituent of the articular cartilage matrix proteins, and immunization with native $\mathrm{CII}$ in adjuvant induces autoimmune polyarthritis by stimulating the cross-reactive immune response to homologous collagen [4]. The generation of CII-specific antibodies is required for progression of CIA. CII antibodyinduced arthritis (CAIA) is a kind of murine RA model that can be induced by passive transfer of antibody to CII [5] and is used to evaluate therapeutic effects in inflammatory arthritis [6].

The pathogenesis of RA is unclear, although clinical trials show that proinflammatory cytokines such as tumor necrosis factor- $\alpha$ (TNF- $\alpha$ ) and IL- $1 \beta$ produced by synovial fibroblasts and immune cells play a pivotal role in the maintenance of RA [7-10]. To determine 
whether in a single knee joint in the CAIA model can provide a therapeutic reference, we measured the concentration of IL- $1 \beta$ in irrigation fluid and in serum, the relative expression level of IL- $1 \beta$ mRNA in synovial tissue and the foot, and histopathological changes in the knee and ankle joints.

\section{Material and methods}

\subsection{Mice}

Male BALB/cByJNarl (BALB/c) mice were purchased at age six weeks from National Laboratory Animal Center (Taiwan) and subsequently bred and maintained under specific pathogen-free conditions in the Laboratory Animal Center of National Defense Medical Center (Taipei, Taiwan).

\subsection{Induction of arthritis in mice}

An arthritogenic monoclonal antibody (mAb) cocktail and lipopolysaccharide (LPS) were purchased from Immuno-Biological Laboratories (Hamburg, Germany) (Chemicon, Germany). Arthritis was induced by the method of Terato et al. [11] using an arthritogenic $\mathrm{mAb}$ cocktail that contained four mAbs (F10, A2, D8, and D1) in equal amounts. Three clones (F10, A2, and D8) were of type IgG2a, and one clone (D1) was type IgG2b. To induce arthritis, each mouse was injected intravenously with $2 \mathrm{mg}$ of anti-CII mAbs followed by an intraperitoneal injection of $50 \mu \mathrm{g}$ (BALB/c background) LPS (Escherichia coli 0111:B4) three days later. Isotype IgG (anti-mouse IgG, 2 mg, Jackson Lab.) supplied with LPS or only LPS injected groups were applied in same condition.

\subsection{Clinical assessment of arthritis}

Arthritis development was monitored in the four limbs using a macroscopic scoring system. Briefly, one point was given for each swollen or red toe; one point for each swollen joint (metatarsal-phalangeal joints, metacarpal-phalangeal joints, proximal interphalangeal joints, and distal interphalangeal joints); and five points for a swollen ankle (maximum score $=$ 15 per limb and 60 per mouse) [12]. The mice were examined on days $0,3,7,10$ and [14] after the mAb injection. The thickness of each paw was measured in a noncontact manner using a Simplified Geometry Measurement System (Advanced Design Research Tech- nology Co., Ltd). Images of the paws of each mouse were recorded three times. One trained researcher who was blinded to group treatments evaluated the image data independently.

\subsection{Histological examination}

The ankle and knee joints were fixed in $10 \%$ formalin, decalcified, trimmed, and embedded. Sections were prepared from the tissue blocks and stained with hematoxylin and eosin. Histopathological scoring was performed as described below. Ankle joints of arthritic mice were given inflammatory scores of $0-5$ to describe the inflammation according to the following criteria: 0 , normal; 1, minimal infiltration of inflammatory cells in the periarticular area; 2 , mild infiltration; 3 , moderate infiltration; 4, marked infiltration; and 5, severe infiltration [13]. Three independent observers scored each slide, and the average score was used.

\subsection{RNA isolation, reverse transcription, and quantitative polymerase chain reaction $(P C R)$}

Total RNA was isolated using the Trizol method. Footpad tissues were homogenized in Trizol lysis buffer followed by chloroform extraction (Life Technologies). The RNA was eluted with $20 \mu$ l of RNase-free water. All RNA was quantified by spectrophotometer, and the optical density (OD) 260/280 nm ratio was determined. For cDNA synthesis, $5 \mu \mathrm{g}$ total RNA was reverse transcribed at $50^{\circ} \mathrm{C}$ for 60 min using 200 units of Superscript III reverse transcriptase (Invitrogen). The primer sequence was as follows: IL1- $\beta$, forward primer (5'-CCAGCAGGTTATCATCATCATCC), reverse primer (5'-CTCGCAGCAGCACATCAAC); and GAPDH, forward primer (5' -TGGCAAAGTGGAGATTGTTGCC), reverse primer (5'-AAGATGGTGATGGGCTTCCCG). The SYBR Green master mix kit (Bio-Rad) was used for all reactions with real-time PCR. Briefly, PCR was performed as follows: $94^{\circ} \mathrm{C}$ for 2 min followed by 40 cycles of denaturation; annealing; and extension at $94^{\circ} \mathrm{C}$ for $15 \mathrm{~s}, 64^{\circ} \mathrm{C}$ for $30 \mathrm{~s}$, and $72^{\circ} \mathrm{C}$ for $45 \mathrm{~s}$; and final extension at $72^{\circ} \mathrm{C}$ for $10 \mathrm{~min}$. The PCR reaction was performed in triplicate for each sample for all the products and for the GAPDH control. Ratios for each product relative to GAPDH mRNA were calculated for each sample. The data presented are expressed as the fold-increase or fold-decrease in mRNA level. For all real-time PCR assays, the products were run out on a gel to confirm the presence of a single band. 
A

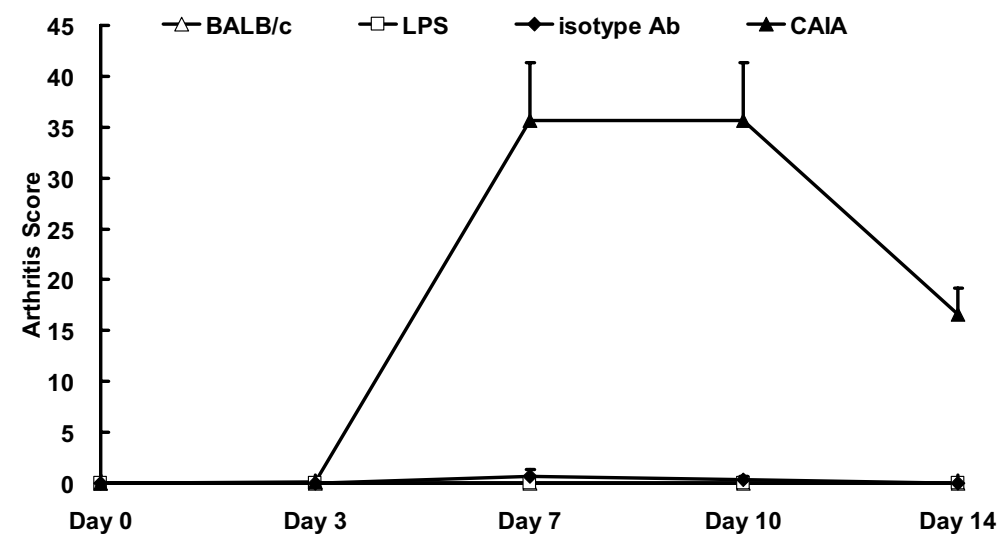

B

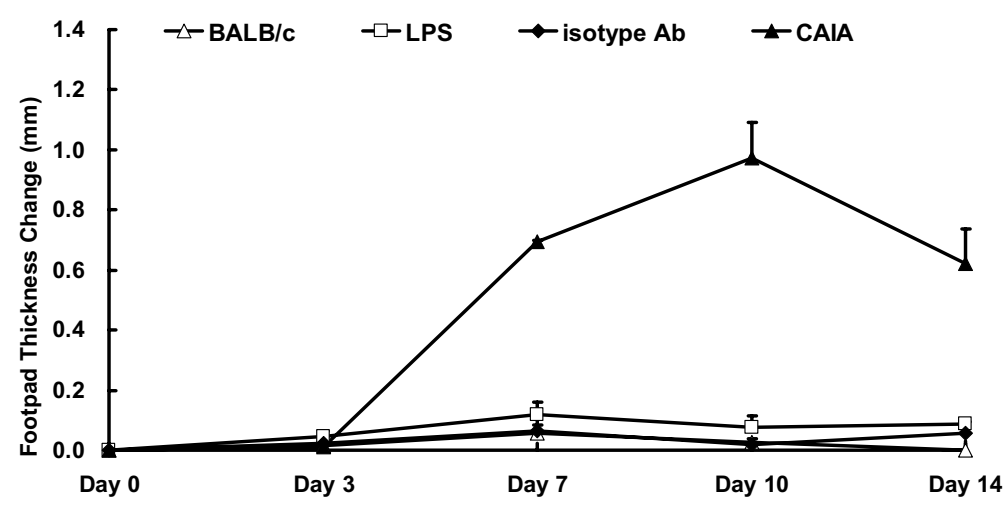

Fig. 1. Inflammation produced in a murine CAIA model. The mice were examined on days 0, 3, 7, 10 and 14 after the mAb injection. (A) Time course of the changes in arthritis score showing dramatic changes on days 7 and 10. The arthritis scores drop obviously on day 14. (B) Footpad thickness increased markedly from day 3 to 7 and was much higher on days 7 to 10 compared with baseline. There was little change in arthritis score and footpad thickness in normal control, LPS injection group and Isotype IgG injection group mice $(n=3)$. Values represent the mean \pm SEM. $P<0.001$ in day 7,10 and 14 .

\subsection{Cytokine assay}

Knee joint fluid irrigation with $300 \mu \mathrm{l}$ of PBS and serum from BALB/c mice were harvested on day 0,3 , 7, 10 and [14] and an enzyme-linked immunosorbent assay using purified monoclonal antibody-coated plates was used to measure IL1- $\beta$ concentration. All procedures followed the manufacturer's protocol (R \& D Systems, Minneapolis, MN, USA). Cytokine concentration was measured using an MRX microplate reader (Dynex Technologies, Chantilly, VA, USA) at $450 \mathrm{~nm}$ (reference $540 \mathrm{~nm}$ ).

\subsection{Statistical analysis}

Data were analyzed by the Mann-Whitney U test and are expressed as mean \pm SEM. A $P$ value $<0.05$ was considered significant.

\section{Results}

\subsection{Systemic inflammation reflected changes in the arthritis score and footpad thickness in the acute stage of CAIA}

One day following the injection of LPS (four days after injection of CII mAbs), the mice developed diarrhea and general weakness, and their activity decreased; body weight decreased and remained low until day 10 after induction of CAIA. Slight signs of swelling were observed on day 5, and these continued to increase until days 7-10, when the swelling and redness peaked. The arthritis score was $0 \pm 0$ in normal mice $(n=$ 3). Arthritis scores increased suddenly between days 3 and 7 , and were highest between days 7 and 10, then moderately decreased on day 14 (Fig. 1A); the mean 

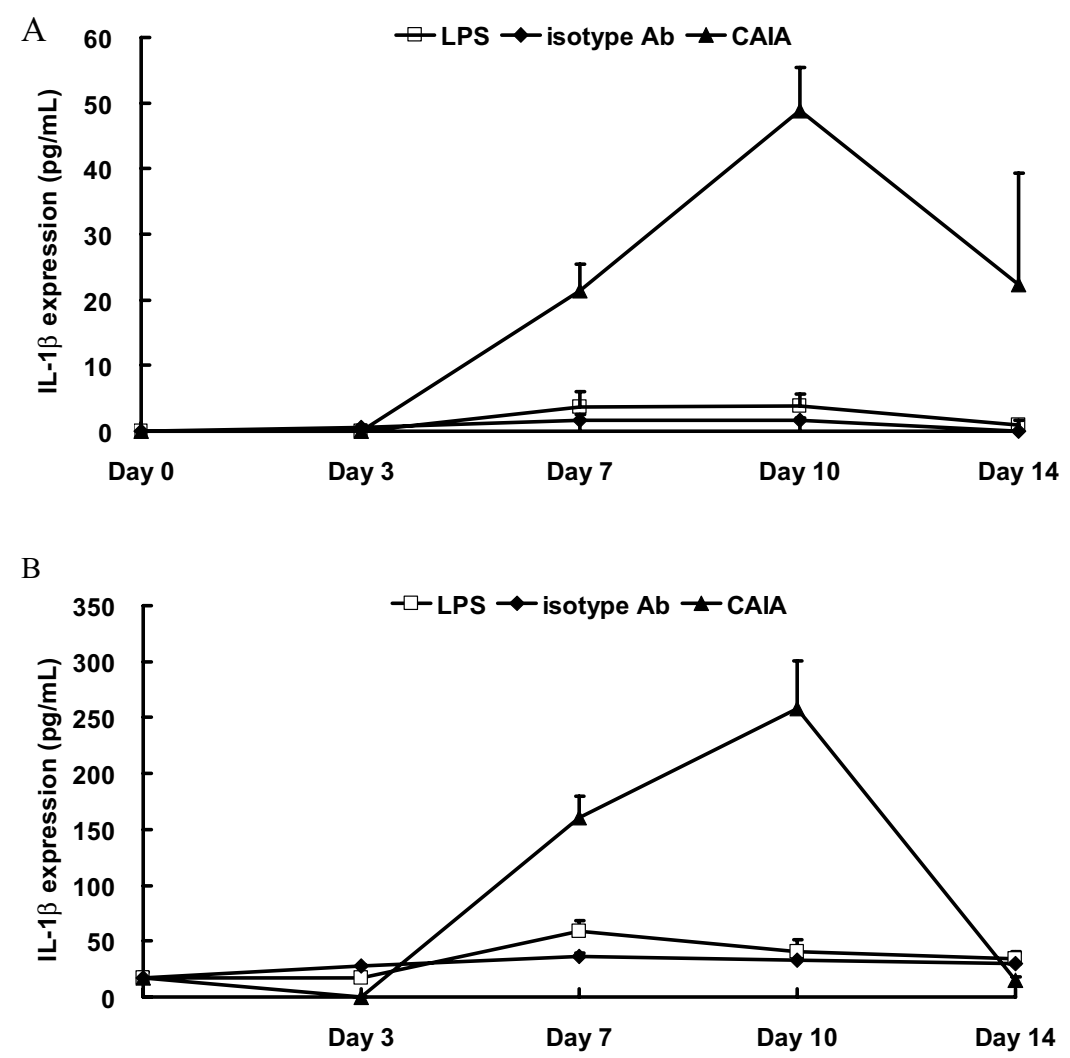

Fig. 2. IL-1 $\beta$ expression in CAIA. (A) IL-1 $\beta$ expression in serum. (B) IL-1 $\beta$ expression in knee joint irrigation. Values represent the mean \pm SEM.

score was $35.63 \pm 5.35$ on day $7,35.66 \pm 5.33$ on day $10(n=8, P<0.001)$, and $16.643 \pm 2.509$ on day 14 ( $n=7, P<0.01)$. The significant difference in disease severity was observed between control mice, isotype IgG injected, LPS injected, and CAIA groups. Footpad thickness increased dramatically from days 3 to 7 and remained high on day 10 , then decreased on day 14 (Fig. 1B). Compared with the baseline value, the footpad thickness increased by $0.694 \pm 0.116 \mathrm{~mm}$ on day 7 , by $0.975 \pm 0.18 \mathrm{~mm}$ on day $10(n=8 ; P<$ $0.001)$ and by $0.623 \pm 0.133 \mathrm{~mm}$ on day $14(n=7$; $P<0.01)$. These data indicate that the pathogenesis developed systemically. The changes of arthritis scores and footpad thickness in isotype IgG injected group and LPS injected group were almost the same as normal control group.

\subsection{IL-1 $\beta$ concentration increased in irrigation fluid from the knee joint and serum in the acute stage of CAIA}

There was a significant difference between CAIA and normal mice for IL- $1 \beta$ concentration in the serum and the irrigation fluid from the right knee and left knee. There was no significant difference between these variables in the irrigation fluid from the right knee and left knee. IL- $1 \beta$ concentration was lower in the serum than in the irrigation fluid from the knee joints. On day 10 , the serum IL-1 $\beta$ concentration was $48.81 \pm 6.68$ $\mathrm{pg} / \mathrm{mL}$ in CAIA mice $(n=8)$ and $29.40 \pm 3.43 \mathrm{pg} / \mathrm{mL}$ in normal mice $(P<0.05)$. At the same time, IL$1 \beta$ concentration in irrigation fluid from the right knee joint was $209.60 \pm 44 \mathrm{pg} / \mathrm{mL}$ in CAIA mice $(n=8)$ and $15.70 \pm 7.8 \mathrm{pg} / \mathrm{mL}$ in normal mice. IL- $1 \beta$ concentration in irrigation fluid from the left knee joint was $306.30 \pm 69.2 \mathrm{pg} / \mathrm{mL}$ in CAIA mice $(n=8)$ and 18.75 $\pm 9.6 \mathrm{pg} / \mathrm{mL}$ in normal mice $(P<0.01)$. Kinetic expression of IL- $1 \beta$ in serum was presented in Fig. 2, and the data from CAIA group were significantly different from other groups on day 7,10 and $14(P<0.001)$ ( $n=3$ on day $3, n=4$ on day 7 and $n=3$ on day 14 in isotype IgG injected and LPS injected group). The similar expression kinetics of IL- $1 \beta$ were observed in knee irrigation and sera of CAIA group, but the level is much higher in knee irrigation than in serum. There 
A

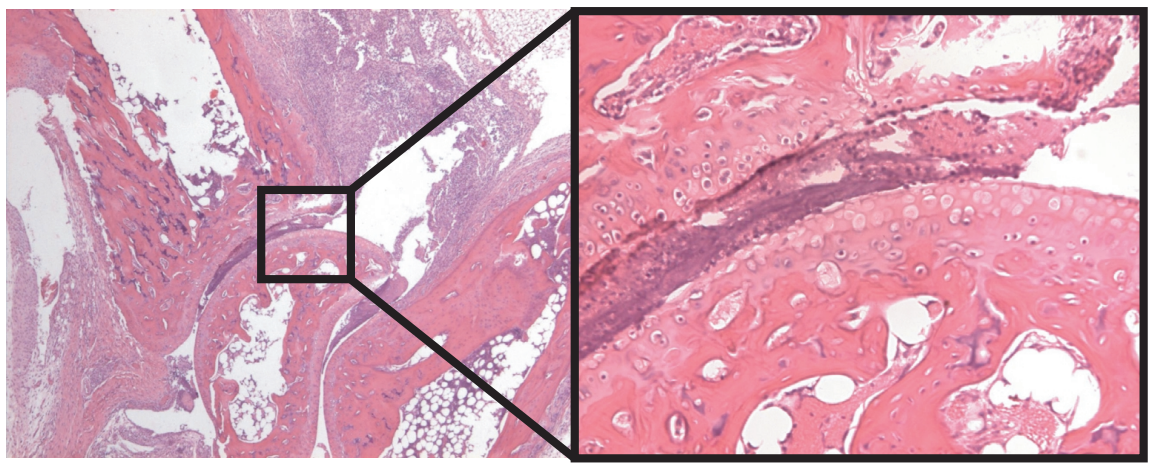

B

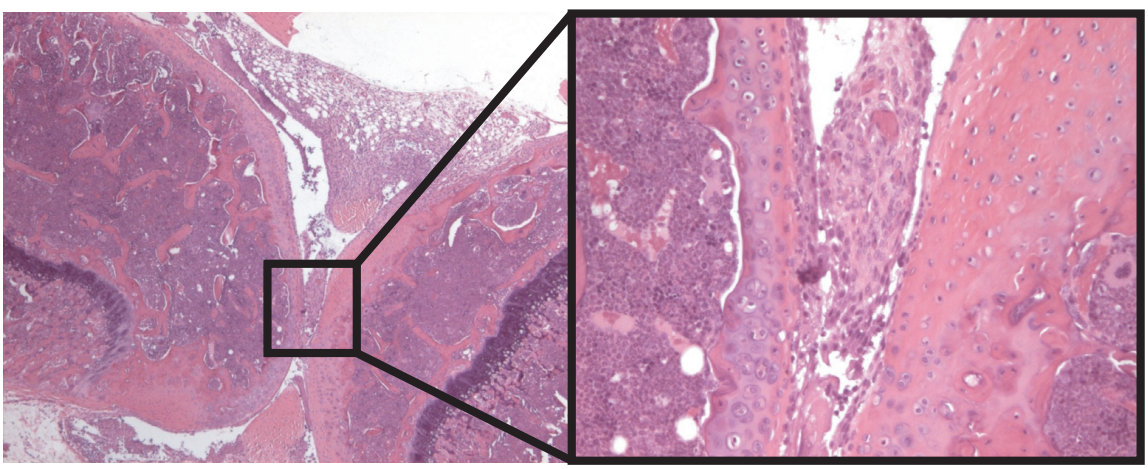

$\mathrm{C}$

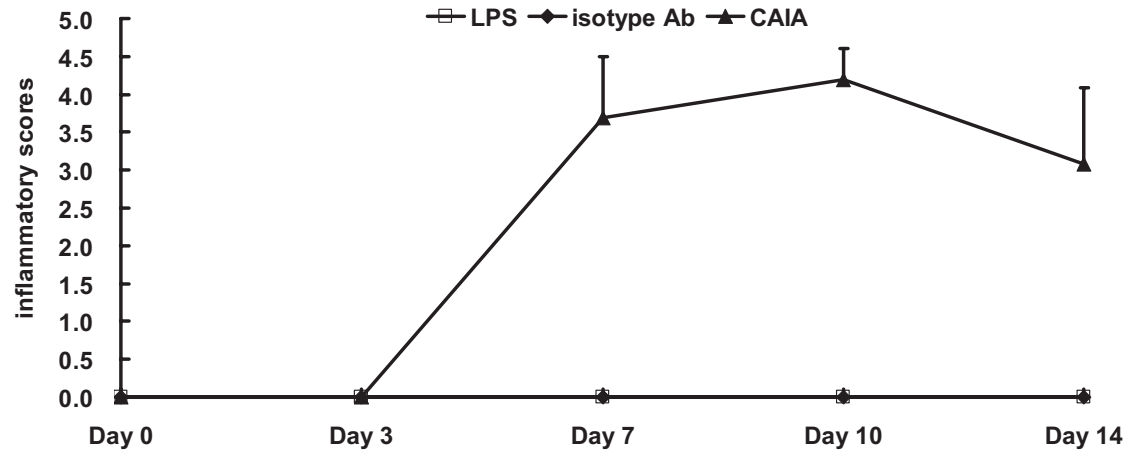

D

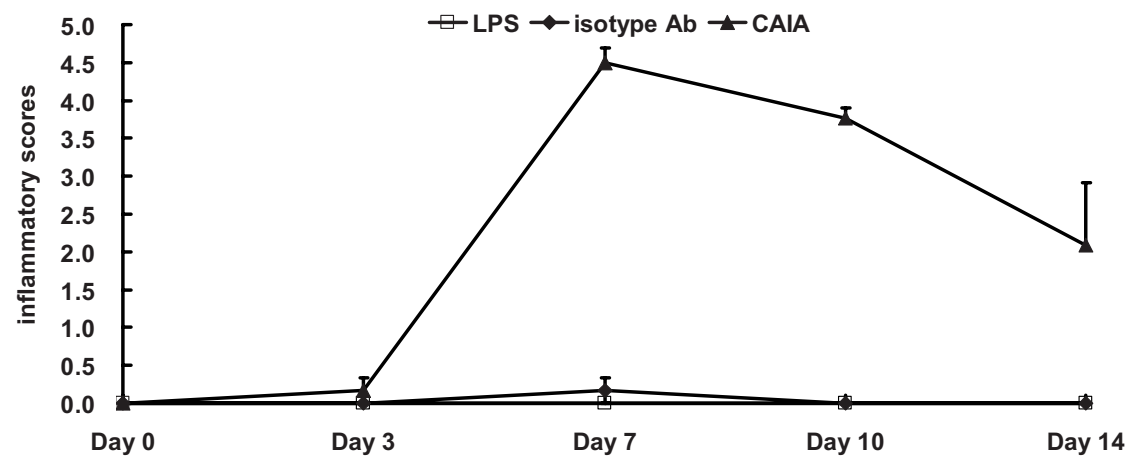

Fig. 3. The histological change was scored in the knee and ankle joint of CAIA mice. Representative photomicrographs are shown at original magnification $\times 100$. (A) Ankle joint in CAIA on day 10. Inflammatory cells infiltration in synovium tissue and joint were recognized. The excudate and debrites were also recognized in joint. (B) Knee joint in CAIA on day 10. (C) Inflammatory score in ankle joint. (D) Inflammatory score in knee joint. 
is no significant difference between other group on day $3,7,10$, and 14 .

\subsection{IL-1 $\beta$ mRNA was highly expressed in synovial tissue of the knee and footpad in the acute stage of CAIA}

On day 10 , the relative expression levels of IL- $1 \beta$ mRNA were $1505.61 \pm 681.2$ in the knee joint $(n=$ $10)$ and $1583.74 \pm 907.5$ in the footpad $(n=14)$. There was no significant difference in IL- $1 \beta$ mRNA expression level between the knee joint and footpad on day 10.

\subsection{Histopathological changes in the knee joint and ankle joint in mice with CAIA}

The histology also showed that inflammation developed locally in the ankle and knee joint areas, as indicated by the infiltration of immune cells, including neutrophils, macrophages, and some lymphocytes; neutrophils were the predominant type of immune cell. Vascularity increased in the inflamed synovium. On day 10 , the inflammatory score reached a mean of 3.84 \pm 0.22 in the left knee, $3.75 \pm 0.26$ in the left foot, $3.63 \pm 0.33$ in the right knee, and $2.81 \pm 0.56$ in the right foot $(n=8)$, indicating a marked inflammatory response. There was no significant difference in inflammatory score between the right and left knee joint or ankle joint (Fig. 3). The average inflammatory score in knee joint was $4.5 \pm 0.189$ on day $7(P<0.001)$ $(n=4), 3.8 \pm 0.143$ on day $10(P<0.001)(n=8)$ and $2.1 \pm 0.812$ on day $14(P<0.05)(n=3)$ in CAIA group (Fig. 3).

\section{Discussion}

CAIA is commonly used as a model of RA for screening of antirheumatic drugs because it is similar to human RA [5]. CAIA offers several key advantages over the classic CIA model, including rapid disease onset, high uptake rate, synchronicity, and the capacity to use genetically modified mice, such as transgenics and knockouts [14]. Our aim is to develop a therapeutic reference in a single knee joint using the CAIA model to simplify and the lower the cost of research on RA because we can compare therapeutic results between the knee joints in individual mice.

There were no previous report about IL- $1 \beta$ concentration in knee joint in CAIA model and only a few re- ports about IL- $1 \beta$ in serum and footpad. Kagari and his colleagues previously reported that the levels of IL- $1 \beta$ in the hind footpads were low from days 0 to 3 , slightly increased from day 3 , and reached a plateau on day 5 , but plasma level of IL- $1 \beta$ remained very low from days 0 to 7 post-LPS injection [15]. IL- $1 \beta$, IL- 6 and TNF- $\alpha$ were also elevated transiently in serum after LPS injection and reached a peak at 2 to $4 \mathrm{~h}$. Other reports also suggest that IL-6 in sera and hind paw is not involved in the development of CAIA [15-18]. Although the concentration of TNF- $\alpha$ in hind paw was lower than the lower detection limit of ELISA from days 0 to 7, a transient elevation of the TNF- $\alpha$ level was confirmed from days 3 to 4 [15]. IL- $1 \beta$ has been reported to positively correlate with the arthritis score in footpad [15]. In our results, the serum level of IL- $1 \beta$ in CAIA was $48.81 \pm 6.68 \mathrm{pg} / \mathrm{mL}$ on day 10 but the level in knee joint irrigation was much higher $(209.60 \pm 44 \mathrm{pg} / \mathrm{mL})$ at the same time, suggesting that IL- $1 \beta$ in joint irrigation is a good candidate marker for CAIA. Although the inflammatory scores differ between the right knee, left knee, right ankle, and left ankle joints, the relative expression level of IL- $1 \beta$ mRNA and serum concentration of IL- $1 \beta$ were similar in the knee and ankle joints, and the concentration of IL- $1 \beta$ in irrigation fluid from the knee joints was markedly higher in the CAIA mice than in the control mice. The IL- $1 \beta$ concentration was much higher in the irrigation fluid from the knee joints than in serum in CAIA mice. These results indicate that the major inflammatory changes occurred in the joints.

Our results also indicate that the levels of IL- $1 \beta$ in both sera and knee joint irrigation from LPS-injected mice or from isotype control antibody-injected mice are quite low, indicating that the inflammatory effects in CAIA require both specific antibodies and LPS, and LPS alone is not likely to induce the high level of IL- $1 \beta$ in mice.

There are several advantages of this model: only a small sample of synovial tissue is needed, inflammatory markers may be studied in a small volume of irrigation fluid obtained from the knee joint, fewer animals or smaller doses of drugs are needed, and the responses may be studied in individual joints rather than on the systemic level. However, this model may give incomplete histological information about changes in the tissues. Our data show that IL- $1 \beta$ concentration in the irrigation fluid and IL- $1 \beta$ expression in the knee joint are potential markers of disease progression. This CAIA mode has potential in the evaluation of antiinflammatory effects of drugs in a closed-knee environment. 


\section{References}

[1] Z. Qu, C. Hernandez Garcia, L.M. O’Rourke et al., Local proliferation of fibroblast-like synoviocytes contributes to synovial hyperplasia: results of proliferating cell nuclear antigen/cyclin, c-myc and nucleolar organizer region staining, Arthritis Rheum 37 (1994), 212-220.

[2] G.S. Firestein, Invasive fibroblast-like synoviocytes in rheumatoid arthritis: passive responders or transformed aggressor? Arthritis Rheum 39 (1996), 1781-1790.

[3] N.A. Andriopoulos, J. Mestecky, E.J. Miller et al., Antibodies to native and denatured collagens in sera of patients with rheumatoid arthritis, Arthritis Rheum 19 (1976), 613-617.

[4] D.E. Trentham, A.S. Townes, A.H. Kang, Autoimmunity to type II collagen an experimental model of arthritis, J Exp Med 146 (1977), 857-868.

[5] R. Holmdahl, M. Andersson, T.J. Goldschmidt, K. Gustafsson, L. Jansson and J.A. Mo, Type II collagen autoimmunity in animals and provocations leading to arthritis, Immunol Rev 118 (1990), 193-232.

[6] M. Sakuma, K. Hatsushika, K. Koyama, R. Katoh, T. Ando, Y. Watanabe, M. Wako, M. Kanzaki, S. Takano, H. Sugiyama, Y. Hamada, H. Ogawa, K. Okumura and A. Nakao, TGFbeta type I receptor kinase inhibitor down-regulates rheumatoid synoviocytes and prevents the arthritis induced by type II collagen antibody, Int Immunol 19 (2007), 117-126.

[7] M. Feldmann, F.M. Brennan and R.N. Maini, Rheumatoid arthritis, Cell 85 (1996), 307-310.

[8] J.M. Bathon, R.W. Martin, R.M. Fleischmann et al., A comparison of etanercept and methotrexate in patients with early rheumatoid arthritis, N Eng J Med 343 (2000), 1586-1593.

[9] P.E. Lipsky, D.M.F.M. van der Heijde, E.W. St. Clair et al., Infliximab and methotrexate in the treatment of rheumatoid arthritis, N Eng J Med 343 (2000), 1594-1602.

[10] B. Breshihan, J.M. Alvaro-Gracia, M. Cobby et al., Treatment of rheumatoid arthritis with recombinant human interleukin-1 receptor antagonist, Arthritis Rheum 41 (1998), 2196-2204.

[11] K.D.S. Terato, M. Harper, M. Griffiths et al., Collagen-induced arthritis in mice: synergistic effect of E. coli lipopolysaccharide bypasses epitope specificity in the induction of arthritis with monoclonal antibodies to type II collagen, Autoimmunity 22 (1995), 137-147.

[12] K.S. Nandakumar, J. Bäcklund, M. Vestberg et al., Collagen type II (CII)-specific antibodies induce arthritis in the absence of $\mathrm{T}$ or $\mathrm{B}$ cells but the arthritis progression is enhanced by CII-reactive T cells, Arthritis Res Ther 6 (2004), R544-R550.

[13] J.-Y. Choe, B. Crain, S.R. Wu et al., Interleukin 1 receptor dependence of serum transferred arthritis can be circumvented by Toll-like receptor 4 signaling, J Exp Med 197 (2003), 537542.

[14] L.M. Khachigian, Collagen antibody-induced arthritis, Nat Protoc 1 (2006), 2512-2516.

[15] T. Kagari, H. Doi and T. Shimozato, The Importance of IL-1 $\beta$ and TNF- $\alpha$, and the Noninvolvement of IL-6, in the Development of Monoclonal Antibody-Induced Arthritis, J Immunol 169 (2002), 1459-1466.

[16] A. Okumura, T. Saito, I. Otani, K. Kojima, Y. Yamada, A. Ishida-Okawara, K. Nakazato, M. Asano, K. Kanayama, Y. Iwakura, K. Suzuki, S. Yamagoe, Suppressive role of leukocyte cell-derived chemotaxin 2 in mouse anti-type II collagen antibody-induced arthritis, Arthritis Rheum 58 (2008), 413421.

[17] T. Kagari, D. Tanaka, H. Doi, Y. Iwakura and T. Shimozato, Anti-type II collagen antibody accelerates arthritis via CXCR2-expressing cells in IL-1 receptor antagonist-deficient mice, Eur J Immunol 37 (2007), 2753-2763.

[18] T. Kagari, D. Tanaka, H. Doi and T. Shimozato, Essential role of Fc gamma receptors in anti-type II collagen antibodyinduced arthritis, J Immunol 170 (2003), 4318-4324. 


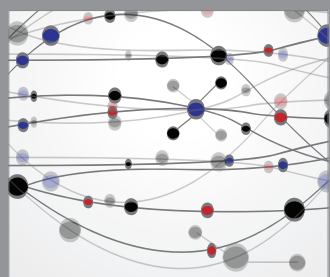

The Scientific World Journal
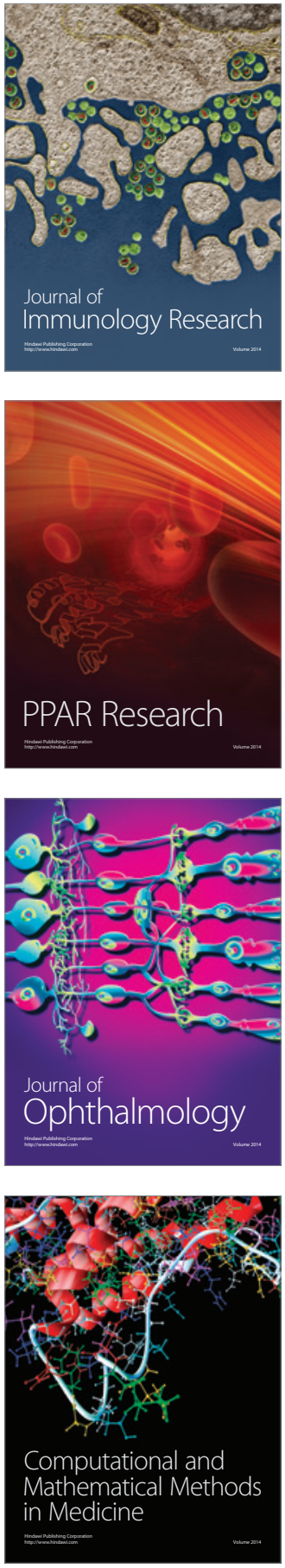

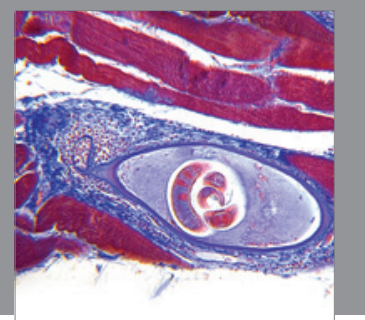

Gastroenterology

Research and Practice
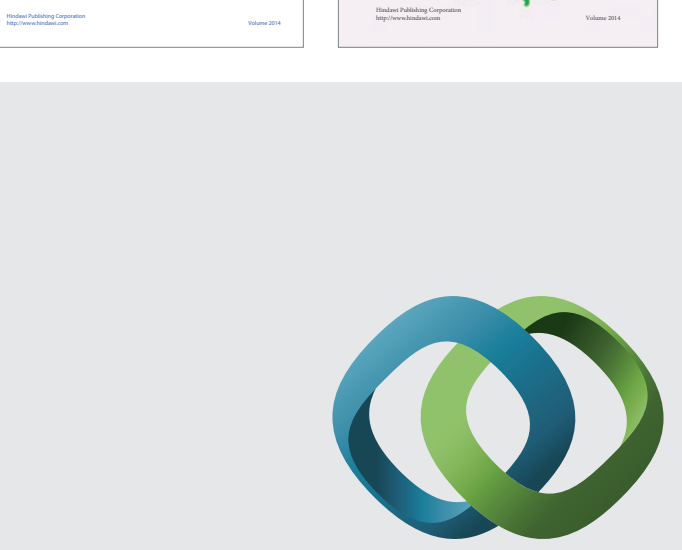

\section{Hindawi}

Submit your manuscripts at

http://www.hindawi.com
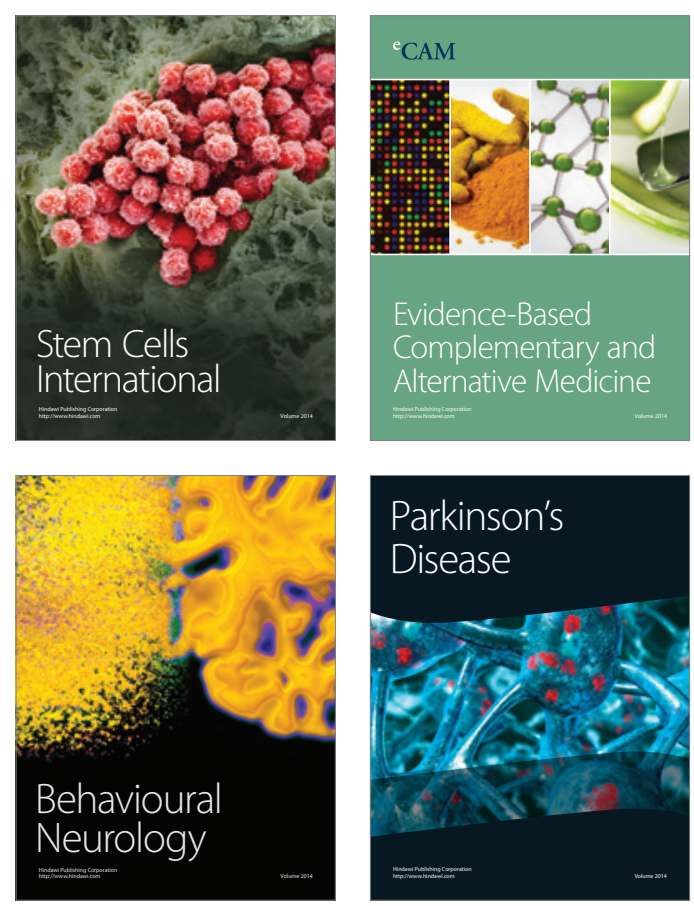

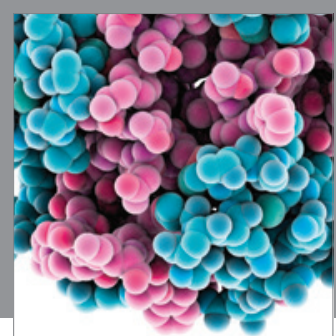

Journal of
Diabetes Research

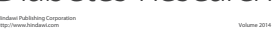

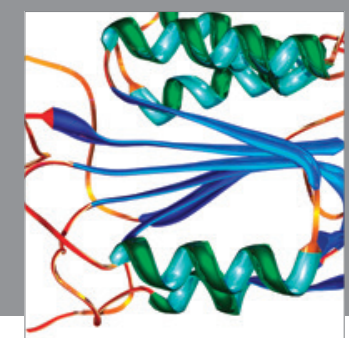

Disease Markers
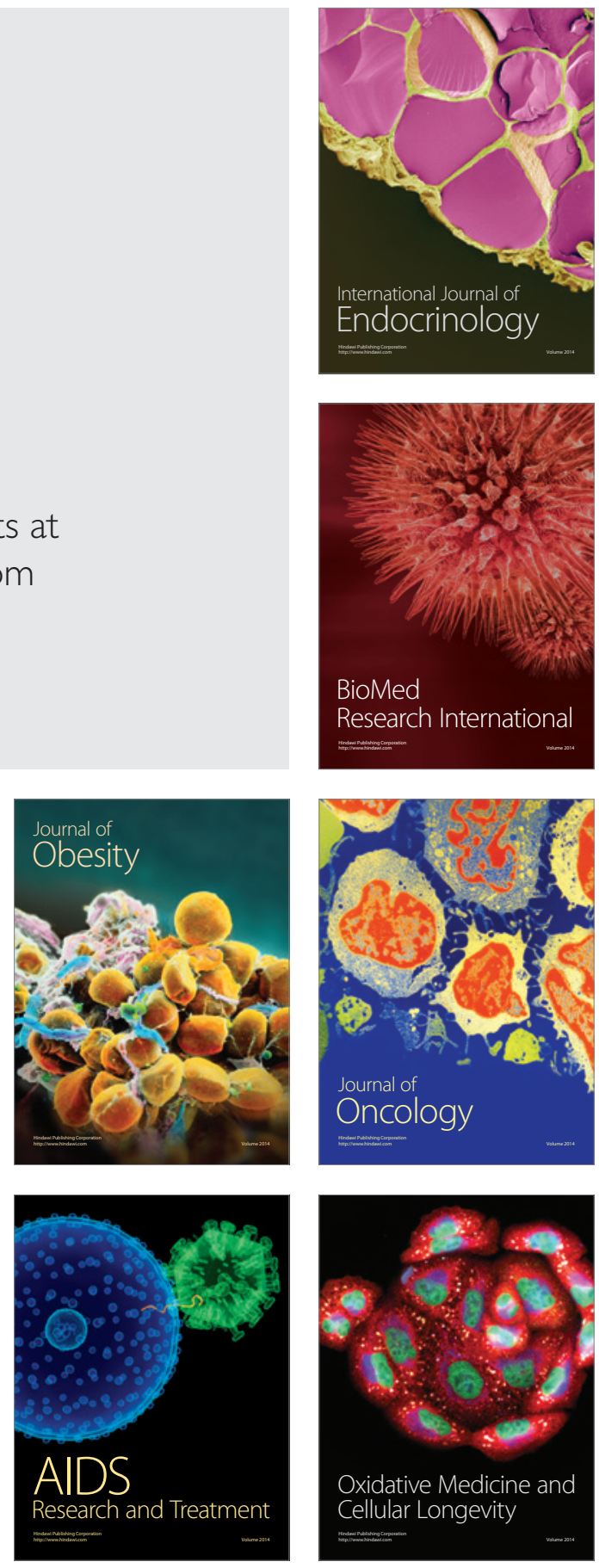